\title{
STUDI TENTANG SANITASI SARANA AIR BERSIH DI PONDOK PESANTREN AL AMIN KELURAHAN PABUARAN KECAMATAN PURWOKERTO UTARA TAHUN 2018
}

\author{
Muhammad Firza Kurnia Robbi ${ }^{1)}$, Khomsatun ${ }^{2)}$ \\ Jurusan Kesehatan Lingkungan, Politeknik Kesehatan Kemenkes Semarang, \\ Jl. Raya Baturraden KM. 12 Purwokerto, Indonesia
}

\begin{abstract}
Abstrak
Air sangat penting bagi kehidupan manusia maka untuk dapat digunakan dan bermanfaat bagi kehidupan manusia, air harus memenuhi persyaratan baik dari segi kualitas maupun kuantitasnya. Penelitian ini bertujuan mengetahui sanitasi sarana air bersih di Pondok Pesantren Al Amin Kelurahan Pabuaran Kecamatan Purwokerto Utara. Jenis penelitian ini termasuk penelitian deskriptif. Pengumpulan data dilakukan dengan cara observasidan wawancara. Data diolah secara deskriptif dilakukan dengan analisis tabel dan prosentase untuk menggambarkan kondisi kualitas air bersih di Pondok Pesantren Al Amin Kelurahan Pabuaran Kecamatan Purwokerto Utara. Pemeriksaan kualitas mikrobiologi air sumur gali menggunakan metode MPN Coliform di laboratorium Kampus 7 Poltekkes Kemenkes Semarang. Hasil penelitian menunjukan bahwa dari 2 sampel air bersih di Pondok Pesantren Al Amin yang menjadi objek penelitian adalah kondisi fisik air meliputi (bau, rasa, warna) dan kondisi mikrobiologi yaitu kandungan coliform tidak memenuhi syarat kesehatan Hasil penelitian menunjukkan kualitas mikrobiologi air sumur gali di Pondok Pesantren Al Amin tidak memenuhi syarat kesehatan dengan hasil SGL $1 \geq 2400$ Coliform per $100 \mathrm{ml}$ sampel dan SGL 21100 Coliform per 100ml sampel. Peneliti menyimpulkan hasil pemeriksaan Coliform pada air bersih di Pondok Pesantren Al Amin tidak memenuhi persyaratan Permenkes RI No. 32 Tahun 2017 tentang Standar Baku Mutu Kesehatan Lingkungan dan Persyaratan Kesehatan Air Untuk Keperluan Higiene Sanitasi, Kolam Renang, Solus Per Aqua, dan Pemandian Umum yaitu 50 per $100 \mathrm{ml} \mathrm{sampel.}$
\end{abstract}

Kata kunci $\quad$ : Coliform; Sumur Gali; Pondok Pesantren

\begin{abstract}
Water is very important for human life. Water can be used and beneficial for human life if the water itself required well with terms of quality and quantity. The aim of the research was to know the facilitation of clean water sanitation in Al Amin Islamic Boarding School Pabuaran Village District of North Purwokerto. The kind of this research was Descriptive. The data collection was observation and interview. The data processed in Descriptive by doing table analysis and percentage to describe the situation of water quality in Al Amin Islamic Boarding School Pabuaran Village District of North Purwokerto. The examining of water microbiological quality of dug well was used in MPN Coliform method in laboratory of Campus 7 Poltekkes Kemenkes Semarang. The result of the research was showed that between 2 clean water samples in Al Amin Islamic Boarding School that became a research object was the physical condition of water, which are contain of; smell, taste, color. And condition of water microbiological quality of dug well in Al Amin Islamic Boarding School was not required with the result based in SGL $1 \geq 2400$ Coliform per $100 \mathrm{ml}$ samples and SGL 21100 Coliform per 100ml samples. The researcher concluded that the examine physic result was got in SGL 1 the water didn't have smell, the water didn't have color, and it had taste. Then the second result was got in SGL 2 the water had taste, the water didn't have color and it had not smell. The microbiological result on Coliform of clean water in Al Amin Islamic Boarding School didn't required with Permenkes RI No. 32 Year 2017 on Environmental Health Standard Standards and Water Health Requirements for Sanitation Hygiene, Swimming Pool, Solus Per Aqua, and Public Baths at 50 per $100 \mathrm{ml}$ samples.
\end{abstract}

Keywords : Coliform, Dug Well, Islamic Boarding School

1) E-mail : firzakurnia015@gmail.com

2) E-mail : khomsatun506@gmail.com 


\section{PENDAHULUAN}

UU RI No 36 Tahun 2009 tentang kesehatan Pasal 162 upaya kesehatan lingkungan ditujukan untuk mewujudkan kualitas lingkungan yang sehat, baik fisik, kimia, biologi maupun sosial serta memungkinkan setiap orang mencapai derajat kesehatan setinggi-tingginya. Tujuan pembangunan kesehatan menuju Indonesia Sehat 2025 adalah meningkatnya kesadaran, kemauan, dan kemampuan hidup sehat bagi setiap orang agar peningkatan derajat kesehatan masyarakat yang setinggi-tingginya dapat terwujud, melalui terciptanya masyarakat, bangsa dan negara Indonesia yang ditandai oleh penduduknya yang hidup dengan perilaku dan dalam lingkungan sehat, memiliki kemampuan untuk menjangkau pelayanan kesehatan yang bermutu, secara adil dan merata, serta memiliki derajat kesehatan yang setinggi-tingginya.

Air memegang peranan penting bagi kehidupan manusia karena dapat digunakan untuk keperluan sehari-hari, namun Air yang digunakan penduduk tidak selalu sesuai dengan syarat kesehatan. Banyak faktor-faktor penyebab pencemaran diantaranya lokasi sumber air dan model kontruksi yang tidak sesuai standar dan seringkali menjadi perantara berbagai penyakit yang membahayakan kelangsungan hidup manusia. Pernyataan tersebut didukung oleh masalah kesehatan manusia melalui perantara air sumur dipengharuhi oleh beberapa faktor diantaranya kondisi geografis, arah aliran air tanah maupun kontruksi bangunan fisik sumur.

Air juga merupakan salah satu sarana media tempat perantara penyakit menular yaitu sebagai media transmisi mikroorganisme penyakit yang berbasis lingkungan yang berasal dari tinja dapat terkontaminasi makanan, maupun minuman melalui air yang tercemar. Berdasarkan alasan ini, maka pengolahan air bersih yang berasal sumber jaringan distribusi mutlak di perlukan untuk mencegah terjadinya kontak dengan kotoran dan tinja yang mengandung bakteri patogen. Sumur gali adalah satu sarana penyediaan air bersih dengan cara menggali tanah sampai mendapatkan lapisan air dengan kedalaman tertentu yang terdiri dari bibir sumur, dinding sumur, lantai sumur, SPAL dan dilengkapi kerekan timba dengan gulungannya atau pompa. Sumur gali juga merupakan salah satu sumber air bersih permukaan yang paling banyak digunakan masyarakat dan potensial terkontaminasi dengan berbagai macam mikroba. Penyakit menular yang disebabkan oleh air secara langsung di antara masyarakat disebut penyakit bawaan air (waterborne diseases). Hal ini dapat terjadi karena air merupakan media yang baik tempat bersarangnya bibit penyakit (Mulia, 2005:41).

Kualitas mikrobiologi adalah tingkat standar keberadaan jumlah suatu organisme hidup yang berukuran mikroskopis yang tidak bisa dilihat dengan mata telanjang seperti mikroorganisme, mikroba dan protista. Biasanya mikrorganisme tertentu dapat dijadikan indikator kualitas air yang kehadirannya merupakan bukti bahwa air tersebut tercemar, seperti bakteri Coliform dan bakteri tinja. Bakteri Coliform merupakan suatu kelompok bakteri yang digunakan sebagai salah satu indikator kualitas air adanya cemaran mikroba, biasanya bisa melalui kotoran yang kondisinya tidak baik terhadap kualitas air, makanan, maupun minuman. Coliform sebagai suatu kelompok bakteri dicirikan sebagai bakteri berbentuk batang, gram negatif, tidak membentuk spora, aerobik dan anaerobik fakultatif yang memfermentasi laktosa dengan menghasilkan asam yang ditandai dengan terbentuknya gas pada tabung yang telah diinkubasi pada media yang sesuai (Waluyo, 2012).

Berdasarkan latar belakang tersebut, peneliti ingin mengetahui sejauh mana kualitas air bersih yang digunakan masyarakat di Pondok Pesantren Al Amin Kelurahan Pabuaran Kecamatan Purwokerto Utara. Berdasarkan survei pendahuluan, Pondok Pesantren Al Amin yang penulis pilih sebagai objek penelitian terletak di Kelurahan Pabuaran Kecamatan Purwokerto Utara Kabupaten Banyumas. Alasan penulis memilih pondok pesantren ini karena belum pernah diadakan pemeriksaan air bersih dengan parameter mikrobiologi dan fisik, dan juga pernah ditemukan 11 kasus diare yang terjadi pada santri Putra. Permasalahan yang muncul berdasarkan survei pendahuluan ditemukan jarak septic tank dengan sumur kurang dari 10 meter. Pondok Pesantren Al Amin memiliki jumlah santri putra dan putri \pm 400 orang. Pondok Pesantren Al Amin terdapat 2 buah sumur gali, dimana sumur tersebut dijadikan objek penelitian untuk pemeriksaan kualitas mikrobiologi air sumur gali. 


\section{BAHAN DAN METODE}

Jenis penelitian ini merupakan penelitian deskriptif yang dilakukan untuk mengetahui kondisi sanitasi sarana air bersih sumur gali di Pondok Pesantren Al Amin Kelurahan Pabuaran Kecamatan Purwokerto Utara.

Subjek penelitian dalam penelitian ini adalah kualitas fisik dan mikrobiologi air sumur gali yang berjumlah dua sumur gali di pondok pesantren Al Amin Kelurahan Pabuaran Kecamatan Purwokerto Utara. Dalam penelitian ini tidak memakai populasi dan sampel. Penelitian ini diambil keseluruhannya subjek penelitiannya.

Sumber Data dari penelitian ini adalah data primer dan data sekunder. Data primer dalam penelitian ini diperoleh dari hasil observasi dan wawancara langsung terhadap responden, data sumur gali yang diamati dengan menggunakan checklist dan data kualitas air hasil penelitian di laboratorium.

Data sekunder diperoleh dari data-data yang ada di Pondok Pesantren Al Amin Kelurahan Pabuaran Kecamatan Purwokerto Utara mengenai kondisi umum dan denah lokasi. Pengumpulan data dilakukan dengan cara observasi, yaitu Observasi ini dilakukan dengan pengamatan langsung menggunakan checklist pada sumur gali. Wawancara yaitu pengamatan langsung terhadap objek penelitian dengan menggunakan kuesioner. Pengukuran yang digunakan dalam penelitian ini yaitu Pengukuran terhadap parameter yang diteliti dalam hal ini adalah MPN Coliform pada air sumur gali yang digunakan untuk penelitian.

Pengolahan data dilakukan dengan cara editing, yaitu penelitian dengan melakukan pengecekkan terhadap semua data yang sudah terkumpul untuk menghindari kesalahan dan kekurangan. Coding, yaitu Pengelompokan data semua hasil pengukuran dan kuesioner pada masing-masing data yang mempunyai kategori yang sama. Tabulating, yaitu memasukkan data yang telah diklasifikasikan ke dalam bentuk tabel dan narasi.

Analisis data yang digunakan adalah Hasil tabulasi, data yang diperoleh dianalisis dengan menggunakan analisis deskriptif, kemudian hasilnya dibandingkan dengan teori dan standar Permenkes RI No. 32 Tahun 2017 tentang Standar Baku Mutu Kesehatan Lingkungan dan Persyaratan Kesehatan Air Untuk Keperluan Higiene Sanitasi, Kolam Renang, Solus Per
Aqua, dan Pemandian Umum. Etika penelitian yang digunakan adalah Informed Consent (Lembar Persetujuan), yaitu Lembar persetujuan akan diberikan subjek yang akan diteliti. Peneliti akan menjelaskan maksud dan tujuan penelitian yang dilakukan serta dampak yang mungkin terjadi selama dan sesudah pengumpulan data, jika subjek menolak untuk diteliti, peneliti tidak akan memaksa dan tetap menghormati hak - hak responden. Anonimity (Tanpa Nama), yaitu Peneliti akan menjaga keamanan dan kerahasiaan dari responden dengan cara tidak mencantumkan nama lengkap dari responden, melainkan dengan menggunakan inisial, sehingga tidak ada orang yang tahu identitas responden, kecuali peneliti itu sendiri dan pihak - pihak tertentu yang terlibat dalam penelitian. Confidentaly (Kerahasiaan), yaitu Kerahasiaan informasi yang diberikan oleh subjek dijamin oleh peneliti, hanya kelompok data tertentu yang akan dilaporkan sebagai hasil penelitian.

\section{HASIL DAN PEMBAHASAN}

\section{A. Data Umum}

1. Keadaan Geografis

Pondok Pesantren Al Amin merupakan sebuah lembaga pendidikan yang memprioritaskan santrinya untuk belajar Al-Qur'an Pesantren Al Amin berada di Desa Pabuaran Kecamatan Purwokerto Utara Kabupaten Banyumas. Tepat letak geografis Pondok Pesantren Al Amin berada di Jl. Prof H.R Boenyamin Gg. Gunung Sindoro 13 A Pabuaran Purwokerto Utara 53124. Pondok Pesantren Al Amin menempati areal tanah \pm 1 Ha terletak radius $\pm 15 \mathrm{~km}$ sebelah utara kota Purwokerto, tepatnya di Kelurahan Pabuaran Kecamatan Purwokerto Utara. Ketinggian tanahnya $\pm 75 \mathrm{~m}$ di atas permukaan air laut. Pondok Pesantren Al Amin terletak di Jl. Prof H.R Boeyamin Gg. Gunung Sindoro 13 A Pabuaran Purwokerto Utara 53124 Telp (0281) 625452. Sebelah utara desa Sumbang, sebelah selatan desa Sumampir, sebelah barat Baturraden, sebelah timur desa Karang Gintung. Pondok pesantren ini memiliki letak yang cukup strategis. Pertama lokasinya di tengah kota, lokasinya di dekat 
kampus Universitas Jendral Soedirman.

Kedua lokasi ini berada di dalam desa

Pabuaran yaitu di tengah-tengah perumahan warga Desa Pabuaran.

2. Keadaan Demografis

Jumlah keseluruhan santri

Pondok Pesantren Al Amin yaitu 400 santri, yang terdiri dari 100 santri putra dan 300 santri putri. Dari data yang ada Pondok Pesantren Al Amin merupakan pondok pesantren yang jumlah penghuninya lebih banyak perempuan dari pada laki - laki yaitu laki-laki 100 jiwa dan perempuan 300 jiwa dan jumlah penghuni menurut golongan umur yang dalam kategori usia produktif sebanyak 380 jiwa, usia belum produktif sebanyak 9 jiwa, dan 11 jiwa tidak produktif.

\section{B. Data Khusus}

1. Kondisi sarana air bersih di Pondok Pesantren Al Amin Kelurahan Pabuaran Kecamatan Purwokerto Utara.

a. Konstruksi sumur gali

Persyaratan Kontruksi Sumur

Gali menurut Menurut Djasio

Sanropie (1983, h. 76) adalah

Berdasarkan pemeriksaan konstruksi sumur gali yang ada di Pondok Pesantren Al Amin, menunjukkan bahwa 8 variabel pemeriksaan memenuhi syarat sanitasi sumur gali didapatkan dari hasil checklist kontruksi sumur gali yaitu diketahui bahwa kontruksi sumur gali di Pondok Pesantren Al Amin Kelurahan Pabuaran Kecamatan Purwokerto Utara dari 8 variabel $100 \%$ sudah memenuhi syarat.

Persyaratan Kontruksi Sumur Gali menurut Menurut Djasio Sanropie (1983, h. 76) adalah :

1) Dinding sumur harus kedap air sedalam $3 \mathrm{~m}$ dari permukaan tanah untuk mencegah rembesan dari air permukaan.

2) Bibir sumur harus kedap air setinggi $0,5-0,7 \mathrm{~m}$ dari permukaan tanah atau garis batas banjir, untuk mencegah rembesan air bekas pemakain kedalam sumur.

3) Pengambilan air dari dalam sumur sehygienis mungkin, misalnya dilengkapi dengan pompa tangan, tutup sumur, timba gulung dan sebagainya

4) Dinding sumur gali dengan pemasangan batu bata atau batu kali dibuat dengan pemasangan batu kosong dimulai dari dasar sumur sampai pada dinding kedap air diatasnya yaitu pada kedalaman $3 \mathrm{~m}$ dibawah permukaan tanah, guna mengalirkan air tanah kedalam sumur.

5) Lantai sumur dibuat kedap air, jarak tepi lantai sampai tepi luar umur $1 \mathrm{~m}$, tebal lantai minimal $0,20 \mathrm{~m}$ dari tanah, dan bentuk lantai sumur bujur sangkar atau lingkaran.

6) SPAL dibuat kedap air sepanjang $10 \mathrm{~m}$ dari tepi lantai sumur.

7) Sumur gali supaya dilengkapi dengan sumur resapan bagi daerah yang tidak ada tempat penerima air limbahnya.

b. Letak Sumur Gali

Berdasarkan pemeriksaan

konstruksi sumur gali yang ada di Pondok Pesantren Al Amin, menunjukkan bahwa 2 variabel pemeriksaan tidak memenuhi syarat sanitasi sumur gali didapatkan dari hasil checklist letak sumur gali yaitu menunjukan bahwa hasil pemeriksaan letak sumur gali di Pondok Pesantren Al Amin Kelurahan Pabuaran Kecamatan Purwokerto Utara 100\% tidak memenuhi syarat yang meliputi jarak jamban dan septic tank dengan sumber air sumur gali kurang dari radius 10 meter. $100 \%$ memenuhi syarat yang meliputi tidak terletak pada daerah banjir dan sumur resapan lebih rendah dari sumber air tanah.

Menurut Departemen Kesehatan R.I (1990, h.19) persyaratan kesehatan yang harus dipenuhi oleh sarana sumur gali, yaitu sebagai berikut:

1) Jarak sumur gali minimal $10 \mathrm{~m}$ dari sumber pencemar seperti jamban, air kotor atau comberan, tempat pembuangan sampah, 
kandang ternak serta tempat kotoran ternak.

2) Pada letak yang miring maka letak sumur harus lebih tinggi dari sumber pencemar.

3) Sumur gali tidak terletak pada lokasi yang dapat terkena banjir, genangan terutama air hujan.

c. Kedalaman Sumur Gali

Berdasarkan hasil pemeriksaan kedalaman sumur gali $100 \%$ sudah memenuhi syarat sanitasi sumur gali yaitu kedalaman sumur cukup menjamin untuk keluarnya air baik musim penghujan maupun musim kemarau. Sejumlah 2 sumur gali yang menjadi obyek penelitian seluruhnya sudah mencapai permukaan air tanah yang rata-rata kedalaman sumur gali mencapai 10 meter.

d. Teknik Pengambilan Air

Berdasarkan hasil observasi teknik pengambilan air sumur gali yang ada di Pondok Pesantren Al Amin, menunjukkan bahwa 1 variabel pemeriksaan tidak memenuhi syarat sanitasi sumur gali dan 4 variabel memenuhi syarat. menunjukan bahwa hasil observasi teknik pengambilan air sumur gali di Pondok Pesantren Al Amin Kelurahan Pabuaran Kecamatan Purwokerto Utara 100\% memenuhi syarat yang meliputi sumur menggunakan kerekan lebih tinggi dari bibir sumur, ember dan tali ember selalu menggantung, sumur menggunakan pompa listrik serta ember dan tali ember diletakkan sedemikian rupa sehingga memungkinkan tidak terjadinya pencemaran. Namun kedua sumur tersebut tidak menggunakan pompa tangan.

e. Pemeliharaan kualitas sarana sumur gali

Bedasarkan hasil pemeriksaan kualitas sarana sumur gali menunjukkan bahwa 6 variabel memenuhi syarat sarana sumur gali. Hasil pemeriksaan kualitas sarana sumur gali di Pondok Pesantren Al Amin Kelurahan Pabuaran Kecamatan Purwokerto Utara 100\% memenuhi syarat yang meliputi kerekan diberi minyak pelumas, ember yang telah rusak selalu diperbaiki, dinding yang telah rusak selalu diperbaiki, bibir sumur yang telah rusak selalu diperbaiki, lantai bebas dari lumut, serta ember bebas dari lumut.

2. Kualitas fisik air sumur gali di Pondok Pesantren Al Amin Kelurahan Pabuaran Kecamatan Purwokerto Utara.

Berdasarkan hasil pemeriksaan sampel air sumur gali yang di lakukan pada tanggal 25 April 2018 untuk pemeriksaan secara fisik bau, rasa dan warna pada air sumur gali di Pondok Pesantren Al Amin Keluarahan Pabuaran Kecamatan Purwokerto Utara didapatkan hasil sebagai berikut:

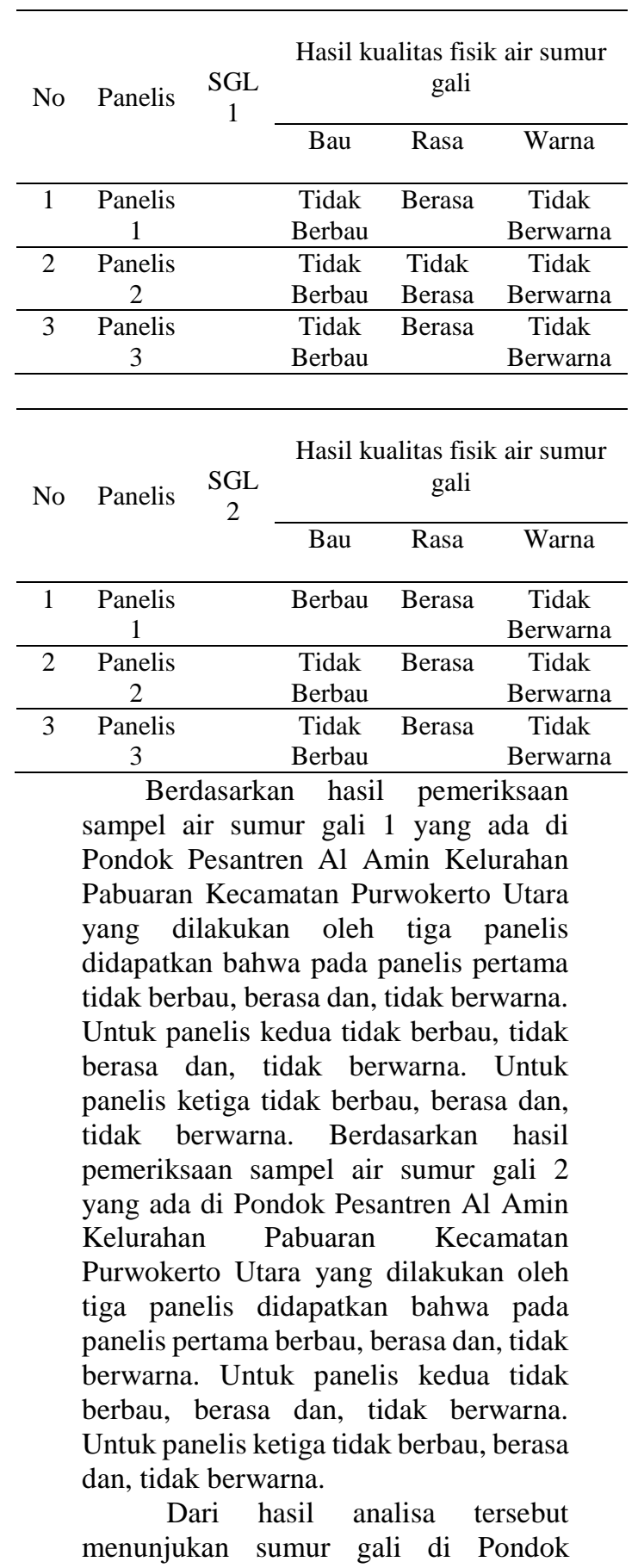


Pesantren Al Amin Kelurahan Pabuaran Kecamatan Purwokerto Utara masih ada yang tidak sesuai standar Permenkes RI Nomor 32 Tahun 2017 Tentang Standar Baku Mutu Kesehatan Lingkungan dan Persyaratan Kesehatan Air Untuk Keperluan Higiene Sanitasi, Kolam Renang, Solus Per Aqua, Dan Pemandian Umum.

Dilihat dari hasil pemeriksaan sumur gali yang masih bau, dan berasa asam dapat disebabkan oleh beberapa faktor diantaranya struktur tanah yang kurang baik akibat hujan deras atau hujan terus-menerus yang menyebabkan tanah disekitar sumur menjadi lunak atau berlumpur sehingga berefek terhadap air sumur serta kurangnya jarak septic tank dengan sumur gali kurang dari 10 meter.

3. Total bakteri Coliform pada air sumur gali di Pondok Pesantren Al Amin Kelurahan Pabuaran Kecamatan Purwokerto Utara

Penelitian pada sumur gali yang diperoleh dari 2 sumur gali di Pondok Pesantren Al Amin Kelurahan Pabuaran Kecamatan Purwokerto Utara bertujuan untuk mengetahui total bakteri coliform. Pemeriksaan dilakukan dengan metode MPN (Most Probable Number) yang dilakukan di laboratorium Kampus 7 Poltekkes Kemenkes Semarang pada tanggal 25 April 2018.

Hasil pemeriksaan uji kualitas mikrobiologi total Coliform pada sumur gali yang ada di Pondok Pesantren $\mathrm{Al}$ Amin Kelurahan Pabuaran Kecamatan Purwokerto Utara sebagai berikut :

\begin{tabular}{|c|c|c|c|c|c|}
\hline No & $\begin{array}{c}\text { Titik } \\
\text { Sampli } \\
\text { ng }\end{array}$ & Hasil & $\begin{array}{c}\text { Kadar } \\
\text { Maksi } \\
\text { mal } \\
\text { Yang } \\
\text { diperbo } \\
\text { lehkan } \\
\text { Air } \\
\text { Bersih }\end{array}$ & Satuan & Ket \\
\hline 1. & SGL 1 & $\begin{array}{c}\geq \\
2400\end{array}$ & 50 & $\begin{array}{c}\text { Per } 100 \\
\mathrm{ml} \\
\text { Sampel }\end{array}$ & $\begin{array}{c}\text { Tidak } \\
\text { Memen } \\
\text { uhi } \\
\text { Syarat } \\
\end{array}$ \\
\hline 2. & SGL 2 & 1100 & 50 & $\begin{array}{c}\text { Per } 100 \\
\mathrm{ml} \\
\text { Sampel }\end{array}$ & $\begin{array}{c}\text { Tidak } \\
\text { Memen } \\
\text { uhi } \\
\text { Syarat }\end{array}$ \\
\hline
\end{tabular}

Dapat diketahui bahwa hasil pemeriksaan laboratorium terhadap 2 sampel air sumur gali mengandung bakteri coliform yang tidak memenuhi syarat menurut Peraturan Menteri Kesehatan Nomor 32 tahun 2017 tentang Standar Baku Mutu Kesehatan Lingkungan dan Persyaratan Kesehatan
Air Untuk Keperluan Higiene Sanitasi, Kolam Renang, Solus Per Aqua, dan Pemandian Umum.

Hasil pemeriksaan kualitas mikrobiologi air sumur gali di Pondok Pesantren Al Amin yang dilaksanakan di laboratorium Kampus 7 Poltekkes Kemenkes Semarang diketahui bahwa sampel SGL 1 memiliki total bakteri coliform sebesar $\geq 2400$ per $100 \mathrm{ml}$ sampel sedangkan sampel SGL 2 memiliki total bakteri coliform sebesar 1100 per $100 \mathrm{ml}$ sampel. Kedua sampel air sumur gali tersebut dikatakan tidak memenuhi syarat karena melebihi standar yang telah ditetapkan oleh Peraturan Menteri Kesehatan Republik Indonesia Nomor 32 Tahun 2017 tentang Standar Baku Mutu Kesehatan Lingkungan dan Persyaratan Kesehatan Air Untuk Keperluan Higiene Sanitasi, Kolam Renang, Solus Per Aqua, dan Pemandian Umum yaitu kadar maksimal yang diperbolehkan air bersih sebesar 50 per $100 \mathrm{ml}$ sampel.

Jarak sumur gali dengan sumber pencemar seperti jamban dan septic tank dapat berpengaruh terhadap kandungan bakteri Coliform pada air sumur gali. Menurut Depkes RI Dirjen PP \& PL Direktorat Penyehatan Lingkungan (2007) menyatakan bahwa apabila letak sumber pencemar lebih tinggi dari sumber air dan diperkirakan air tanah mengalir ke sumur maka jarak minimal sumur terhadap sumber adalah $11 \mathrm{~m}$ dan apabila letak sumber pencemar sama atau lebih rendah dari sumur maka jarak minimal sumur gali tersebut $9 \mathrm{~m}$.

Dampak yang dapat timbul dari jarak sumur gali dengan sumber pencemar yang kurang memenuhi syarat adalah terjadinya penyebaran bakteri Coliform melalui perembesan ke dalam sumur gali. Hal tersebut dapat dipengaruhi karena kontaminasi bakteri bergerak mengikuti arus atau aliran air tanah.

Dengan jarak tersebut diharapkan pergerakan bakteri Coliform tidak dapat menembus kedalam sumur gali. Selain jarak antara sumur gali dengan jamban, sumber pencemar lainnya adalah air kotor/comberan, tempat pembuangan sampah, dan kandang ternak seperti kandang ayam dan kambing dimana jarak dengan sumur gali masih kurang dari $11 \mathrm{~m}$. 


\section{SIMPULAN}

Berdasarkan hasil penelitian dan pembahasan tentang sanitasi sarana air bersih di Pondok Pesantren Al Amin Kelurahan Pabuaran Kecamatan Purwokerto Utara dapat diambil kesimpulan sebagai berikut:

1. Kontruksi sumur gali pada SGL 1 dan SGL 2 sudah memenuhi persyaratan. Namun dari letak sumur gali tidak memenuhi syarat yang meliputi jarak jamban dan septic tank dengan sumber air sumur gali kurang dari radius 10 meter hal tersebut dapat dilihat risiko pencemaran dengan kategori sedang.

2. Hasil pemeriksaan air bersih dengan parameter fisik didapatkan hasil bahwa pada SGL 1 air tidak berbau, air tidak berwarna dan air berasa. Pada SGL 2 didapatkan hasil bahwa air berasa, lalu air tidak berwarna dan air tidak berbau.

3. Dari hasil pemeriksaan laboratorium menunjukkan bahwa total bakteri Coliform pada air bersih di Pondok Pesantren Al Amin Kelurahan Pabuaran Kecamatan Purwokerto Utara dengan total coliform SGL 1 berjumlah $\geq 2400$ per $100 \mathrm{ml}$ sampel, dan total coliform pada SGL 2 berjumlah 1100 per $100 \mathrm{ml}$ sampel. Hasil pemeriksaan tersebut menyebutkan bahwa kandungan Coliform pada air bersih di Pondok Pesantren Al Amin tidak memenuhi persyaratan Permenkes RI Nomor 32 Tahun 2017 tentang Standar Baku Mutu Kesehatan Lingkungan dan Persyaratan Kesehatan Air Untuk Keperluan Higiene Sanitasi, Kolam Renang, Solus Per Aqua, dan Pemandian Umum yaitu 50 per $100 \mathrm{ml}$ sampel.

\section{DAFTAR PUSTAKA}

Candra, Budiman. 2007. Pengantar Kesehatan Lingkungan. Jakarta: Kedokteran EGC

Djasio Sanropie dkk. 1984. Penyediaan Air Bersih, Akademi Pemilik Kesehatan Tenaga Sanitasi Pusdiklat: Depkes R.I

Anisa Intan Sari Wulan. 2005. Kualitas Air Bersih Untuk Pemenuhan Kebutuhan Rumah Tangga Di Desa Pesarean Kecamatan Adiwerna Kabupaten Tegal. Skripsi. Jurusan Geografi Fakultas Ilmu Sosial. Semarang: Universitas Negeri Semarang
Dwijoseputro, D. 1985. Dasar-Dasar Mikrobiologi, Malang: Djambatan

Departemen Kesehatan R.I. 1985. Pengawasan Kualitas Air Untuk Penyediaan Air Bersih Pedesaan dan Kota Kecil. Jakarta: Ditjen PPM dan PLP

Departemen Kesehatan RI, 2007, Pedoman Penyelenggaraan dan Pembinaan Pos Kesehatan Pesantren, Jakarta: Depkes

Fawanri Herwin Sinabang. 2009. Studi Kualitas Mikrobiologi Air Sumur Gali Di Kelurahan Larangan Kecamatan Larangan Kabupaten Brebes. Karya Tulis Ilmiah. Purwokerto: Kementerian Kesehatan RI Politeknik Kesehatan Semarang Jurusan Kesehatan Lingkungan Purwokerto

Frisian Lufti Intan Risqita. 2016. Hubungan Jarak Sumber Pencemar Dengan Kualitas Mikrobiologis Air Sumur Gali Di Desa Pangebatan Kecamatan Karanglewas Kabupaten Banyumas. Karya Tulis Ilmiah. Purwokerto: Kementerian Kesehatan RI Politeknik Kesehatan Semarang Jurusan Kesehatan Lingkungan Purwokerto

Indan Entjang. 2000. Ilmu Kesehatan Masyarakat. Jakarta: Citra Aditya Bakti

Michael J Pelczar. 2008. Dasar-Dasar Mikrobiologi 2. Jakarta: Universitas Indonesia Press

Rahmawati, Nur Fitri, Rr Eko Susetyorini dan Lud Waluyo. 2016. Kualitas Mikrobiologi Air Sumur Berdasarkan Total Coliform Di Kabupaten Trenggalek. Jurnal Penelitian Program Studi Pendidikan Biologi. Malang: Universitas Muhammadiyah Malang

$\begin{array}{crr}\text { Peraturan Menteri } & \text { Kesehatan } & \text { Republik } \\ \text { Indonesia } & \text { Nomor } \\ \text { 416/Menkes/Per/IX/1990 } & \text { Tentang } \\ \text { Syarat-syarat Dan pengawasan } & \text { Kualitas } \\ \text { Air } & \end{array}$

Peraturan Menteri Kesehatan Republik Indonesia Nomor 32 Tahun 2017 Tentang Standar Baku Mutu Kesehatan Lingkungan dan Persyaratan Kesehatan Air Untuk Keperluan Higiene Sanitasi, Kolam Renang, Solus Per Aqua, dan Pemandian Umum 
Peraturan Pemerintah Republik Indonesia Nomor 82 Tahun $2001 \quad$ Tentang Pengelolaan Kualitas Air Dan Pengendalian Pencemaran Air

Rega Andika Rini. 2017. Hubungan Tingkat Resiko Pencemaran Sumur Gali Dengan Total Coliform Di Desa Klapasawit Kecamatan Kalimanah Kabupaten Purbalingga. Karya Tulis Ilmiah. Purwokerto: Kementerian Kesehatan RI Politeknik Kesehatan Semarang Jurusan Kesehatan Lingkungan Purwokerto

Sabit Darojah. 2015. Tinjauan Sanitasi Dan Perilaku Hidup Bersih Sehat Santri Pondok Pesantren Darussa'adah Desa Kritig Kecamatan Petanahan Kabupaten Kebumen. Karya Tulis Ilmiah. Purwokerto: Kementerian Kesehatan RI Politeknik Kesehatan Semarang Jurusan Kesehatan Lingkungan Purwokerto

Tutut Mugi Rahayu. 2015. Studi Kualitas Air Bersih Sumur Gali Di Dusun Japun Desa Kewangunan Kecamatan Petanahan Kabupaten Kebumen. Karya Tulis Ilmiah. Purwokerto: Kementerian Kesehatan RI Politeknik Kesehatan Semarang Jurusan Kesehatan Lingkungan Purwokerto

Undang-Undang Republik Indonesia Nomor 36 Tahun 2009 Tentang Kesehatan. Jakarta: Presiden Republik Indonesia

Undang-undang Republik Indonesia Nomor 7 Tahun 2004 tentang Sumber Daya Air. Jakarta: Presiden Republik Indonesia 